\title{
FITOTOKSISITAS DAN EFIKASI HERBISIDA AMINOSIKLOPILAKLOR DAN KOMBINASINYA DENGAN GLIFOSAT TERHADAP GULMA PADA PERKEBUNAN KELAPA SAWIT (Elaeis guineensis Jacq.) BELUM MENGHASILKAN
}

\author{
Darso Waluyo, Nanik Sriyani, \& Rusdi Evizal \\ Agroteknologi, Fakultas Pertanian Universitas Lampung \\ Jl. Prof. Soemantri Brodjonegoro, No.1 Bandar Lampung 35145 \\ E-mail : darso_waluyo@yahoo.com
}

\begin{abstract}
ABSTRAK
Penelitian ini bertujuan untuk mengetahui tingkat fitotoksisitas herbisida aminosiklopilaklor dan kombinasi aminosiklopilaklor dengan glifosat, dan triklopir dengan aminopiralid terhadap tanaman kelapa sawit belum menghasilkan, dan untuk mengetahui efikasi aminosiklopilaklor dan kombinasi aminosiklopilaklor dengan glifosat, dan triklopir dengan aminopiralid terhadap pengendalian gulma pada pertanaman kelapa sawit belum menghasilkan (TBM). Hasil penelitian menunjukkan bahwa : (1) aplikasi herbisida aminosiklopilaklor tunggal dosis $50 \mathrm{dan} 100 \mathrm{~g} / \mathrm{ha}$, kombinasi aminosiklopilaklor + glifosat dosis $25+720 \mathrm{~g} / \mathrm{ha}$ dan 50+720 g/ha, dan triklopir + aminopiralid 216+384 g/ha pada perkebunan kelapa sawit tidak meracuni dan tidak mempengaruhi tinggi tanaman kelapa sawit belum menghasilkan; (2) aplikasi herbisida aminosiklopilaklor $100 \mathrm{~g} / \mathrm{ha}$ dan kombinasi aminosiklopilaklor + glifosat dosis $25+720$ g/ha mampu mengendalikan gulma total hingga 4 minggu setelah aplikasi; (3) aplikasi herbisida aminosiklopilaklor 50 dan $100 \mathrm{~g} / \mathrm{ha}$ mampu mengendalikan gulma daun lebar hingga $12 \mathrm{minggu} \mathrm{setelah}$ aplikasi, tetapi semua perlakuan herbisida tidak mampu mengendalikan gulma rumput dan ; (4) aplikasi herbisida aminosiklopilaklor 50 dan $100 \mathrm{~g} /$ ha mampu mengendalikan gulma dominan Richardia brasiliensis hingga 8 minggu setelah aplikasi, tetapi tidak mampu mengendalikan gulma dominan Dactyloctenium aegyptium.
\end{abstract}

Kata kunci: Aminosiklopilaklor, glifosat, fitotoksisitas, gulma, herbisida, sawit TBM, triklopir, aminopiralid

\section{PENDAHULUAN}

Kelapa sawit (Elaeis guineensis Jacq.) adalah tumbuhan industri penting penghasil minyak masak, minyak industri, maupun bahan bakar. Pada tahun 2007, Indonesia merupakan negara produsen kelapa sawit terbesar di dunia dengan luas areal 6,78 juta ha (Ditjenbun, 2008). Walaupun produksi kelapa sawit sudah cukup tinggi, namun besarnya kebutuhan terhadap kelapa sawit mendorong perlunya dilakukan pengelolaan perkebunan yang tepat, terarah, dan efisien untuk meningkatkan kualitas dan produktivitas kelapa sawit, sehingga mampu berkompetisi di pasar internasional.

Salah satu upaya yang dilakukan untuk meningkatkan kualitas dan produktivitas kelapa sawit yaitu dengan intensifikasi lahan. Namun, satu kendala yang dihadapi dalam intensifikasi adalah permasalahan budidaya. Dalam budidaya kelapa sawit, salah satu faktor yang menghambat produktivitas kelapa sawit yaitu gulma. Keberadaan gulma menjadi masalah dalam usaha perkebunan, karena membutuhkan tenaga, biaya, dan waktu yang terus menerus untuk mengendalikannya. Oleh sebab itu, pengendalian gulma sangat penting untuk dilakukan. Metode yang paling banyak digunakan adalah metode kimiawi dengan menggunakan herbisida. Metode ini dianggap lebih praktis dan menguntungkan dibandingkan dengan metode yang lain, terutama jika ditinjau dari segi kebutuhan tenaga kerja yang lebih sedikit dan waktu pelaksanaan yang relatif singkat (Barus, 2007).

MAT28 240SL merupakan herbisida yang memiliki bahan aktif aminosiklopilaklor yang merupakan bahan aktif yang termasuk kedalam golongan pirimidin. Aminosiklopilaklor cepat diserap oleh daun dan akar dan ditranslokasikan ke bagian meristem tumbuhan dan mengganggu kerja auksin. Herbisida ini dapat digunakan untuk gulma daun lebar dan beberapa jenis rumput (Finkelstein dkk., 2008). Glifosat termasuk herbisida non selektif dan diaplikasikan pada saat pasca tumbuh dan diabsorbsi lewat daun, dan tidak berpengaruh bila diaplikasikan lewat tanah. Translokasi terjadi dari dalam ke seluruh bagian tumbuhan termasuk bagian tumbuhan yang ada di dalam tanah (Anderson, 1977). Triklopir merupakan herbisida sistemik yang selektif, mengendalikan gulma berkayu dan berdaun lebar. Ada 2 formula dasar dari triklopir yakni garam triethyamine dan butoksi etil ester. Triklopir dapat segera didegredasikan oleh mikroorganisme dalam tanah 
sehingga tidak menimbulkan residu. Rata-rata paruh hidup triklopir dalam tanah adalah 30 hari (Tu dkk., 2001).

Penelitian ini bertujuan untuk mengetahui tingkat fitotoksisitas herbisida aminosiklopilaklor dan kombinasi aminosiklopilaklor dengan glifosat, serta triklopir dengan aminopiralid terhadap tanaman kelapa sawit belum menghasilkan, dan mengetahui efikasi aminosiklopilaklor dan kombinasi aminosiklopilaklor dengan glifosat, serta triklopir dengan aminopiralid terhadap pengendalian gulma pada pertanaman kelapa sawit belum menghasilkan.

\section{BAHAN DAN METODE}

Penelitian ini dilaksanakan di lahan perkebunan kelapa sawit belum menghasilkan milik petani di Natar, Lampung Selatan dari bulan November 2012 sampai dengan Maret 2013. Alat yang digunakan dalam penelitian ini adalah sprayer punggung, tali, kamera, alat tulis, meteran, cangkul, kuadran, pengaduk, ember, gelas ukur, dan pipet tetes. Bahan yang digunakan dalam penelitian ini adalah: herbisida MAT28 240 SL (aminosiklopilakor $240 \mathrm{~g}^{-1}$ ), Round Up $480 \mathrm{SL}$ (glifosat IPA $480 \mathrm{~g} \mathrm{l}^{-1}$ ), dan Garlon mix 1250 EC (triklopir dan aminopiralid 450 dan $800 \mathrm{gl}^{-1}$ ), serta air.

Penelitian ini disusun dalam Rancangan Kelompok Teracak Sempurna (RKTS) dengan 7 perlakuan dan 3 ulangan (Tabel 1). Data yang diperoleh diuji homogenitasnya dengan Uji Barlett dan aditifitasnya dengan Uji Tuckey, kemudian dilakukan analisis ragam dan uji BNT pada taraf 5\%.

Kriteria lahan yang dipilih adalah lahan dengan tanaman kelapa sawit belum menghasilkan berumur 2 tahun dengan jarak tanam 9x9 m dan komposisi gulma yang terdiri dari gulma golongan daun lebar dan rumput dengan penutupan gulma lebih dari $75 \% .3$ bulan sebelum aplikasi, pengendalian gulma sudah dihentikan. Herbisida diapliaksikan dengan menggunakan sprayer punggung. Sebelum dilakukan aplikasi, dilakukan kaliberasi sprayer dan menghitung volume semprot dengan metode luas dan didapat volume semprot $4001 \mathrm{ha}^{-1}$. Dalam satu satuan percobaan terdiri dari 2 tanaman kelapa sawit belum menghasilkan. Aplikasi dilakukan pada piringan kelapa sawit dengan jarak $3 \mathrm{~m}$ dari batang dengn menggunakan nozel merah. Pada jarak $1 \mathrm{~m}$ dari batang, gulma tidak dikendalikan sehingga luas aplikasi perlakuan adalah $25,12 \mathrm{~m}^{2}$ per satuan percobaan.

Variabel yang diamati pada penelitian ini adalah bobot kering gulma total, bobot kering gulma golongan daun lebar dan rumput, tinggi tanaman, fitotoksisitas herbisida pada daun muda, daun tua dan buah. Pengambilan sampel gulma dilakukan dengan menggunakan kuadran ukuran $50 \mathrm{~cm}$ x $50 \mathrm{~cm}$ sebanyak 2 kuadran pada masing-masing perlakuan. Gulma yang masih segar dipotong tepat pada permukaan tanah kemudian dioven dengan suhu $80^{\circ} \mathrm{C}$ selama 48 jam kemudian ditimbang bobot kering gulma. Tinggi tanaman diukur dari permukaan tanah sampai daun muda dan dilakukan dalam satuan centimeter dengan menggunakan meteran.

Pengamatan fitotoksisitas dilakukan dengan cara skoring 0 (tidak ada keracunan ; $0-5 \%$ bentuk dan atau warna daun tidak normal), 1 (keracunan ringan ; > 5$10 \%$ bentuk dan atau warna daun tidak normal), 2(keracunan sedang ; > 10-50\% bentuk dan atau warna daun tidak normal), 3 (keracunan berat ; > 50-75\% bentuk dan atau warna daun tidak normal ), dan 4 (keracunan sangat berat $;>75 \%$ bentuk dan atau warna daun tidak norma). Seluruh variabel pengamatan diamati pada 2, 4, 8 dan 12 minggu setelah aplikasi.

\section{HASIL DAN PEMBAHASAN}

Gulma golongan daun lebar yang terdapat pada petak percobaan antara lain: Asystasia gangetica,

Tabel 1. Daftar perlakuan percobaan pada tanaman kelapa sawit belum menghasilkan.

\begin{tabular}{llll}
\hline No & \multicolumn{1}{c}{ Perlakuan } & Dosis bahan aktif $\left(\mathrm{g} \mathrm{ha}^{-1}\right)$ & Dosis formulasi $\left(\mathrm{ml} \mathrm{ha}^{-1}\right)$ \\
\hline 1 & Aminosiklopilaklor & 50 & 208 \\
2 & Aminosiklopilaklor & 100 & 416 \\
3 & Aminosiklopilaklor + glifosat & $25+720$ & $104+1500$ \\
4 & Aminosiklopilaklor + glifosat & $50+720$ & $208+1500$ \\
5 & Triklopir dan aminopiralid & $216+384$ & 480 \\
6 & Mekanis & - & - \\
7 & Kontrol & - & - \\
\hline
\end{tabular}


Ageratum conyzoides, Borreria alata, Cleomme rutidosperma, Croton hirtus, Emilia sonchifolia, Euphorbia hirta, Euphorbia geniculata, Hediotys corymbosa, Ipomoea triloba, Mikania michanta, Mitracarpus hirtus, Oxalys barrelieri, Pasiflora foetida, Richardia brasiliensis, Spigelia anthelmia, Stachytarpeta jamasinensis, Synedrella nodiflora, dan Vernonia.

Tabel 2 menunjukkan bahwa pada 2 dan 4 MSA seluruh perlakuan herbisida mampu mengendalikan gulma daun lebar yang terdapat pada petak percobaan. Hal ini ditunjukkan oleh data bobot kering gulma golongan daun lebar pada seluruh petak percobaan yang lebih rendah dibandingkan dengan kontrol. Aminosiklopilaklor 50 dan $100 \mathrm{~g} \mathrm{ha}^{-1}$ mampu menekan gulma daun lebar hingga 93 dan 96\%. Demikian pula halnya dengan kombinasi herbisida aminosiklopilaklor + glifosat $25+720 \mathrm{~g} \mathrm{ha}^{-1}, 50+720 \mathrm{~g} \mathrm{ha}^{-1}$ mampu mekekan gulma daun lebar sebesar 94 dan $83 \%$. Hal ini selaras dengan pernyataan Mohamad dkk. (2010), bahwa herbisida glifosat dosis 400 dan $800 \mathrm{~g} \mathrm{ha}^{-1}$ mampu mengendalikan gulma daun lebar 85 sampai 100\% hingga 4 MSA. Bobot kering gulma perlakuan mekanis yang lebih rendah dari kontrol menunjukan bahwa perlakuan mekanis dapat mengendalikan gulma daun lebar dengan penekan terhadap gulma daun lebar sebesar $99 \%$.

Pada 8 MSA, perlakuan herbisida aminosiklopilaklor tunggal pada dosis 50 dan $100 \mathrm{~g} \mathrm{ha}^{-1}$ dapat menekan pertumbuhan gulma golongan daun lebar sebesar 92 dan 96\%. Hal ini sesuai dengan pendapat Finkelstein dkk. (2008) yang menyatakan bahwa herbisida aminosiklopilaklor dapat mengendalikan gulma daun lebar dengan sangat baik. Pada 12 MSA, perlakuan herbisida aminosiklopilaklor 50 dan $100 \mathrm{~g} \mathrm{ha}^{-1}$ masih mampu menekan pertumbuhan gulma daun lebar sebesar 83 dan 56\%. Hal ini dapat dilihat dari bobot kering gulma daun lebar pada perlakuan tersebut lebih rendah dari kontrol. Sedangkan perlakuan herbisida lainnya dan mekanis sudah tidak mampu menekan pertumbuhan gulma daun lebar.

Gulma golongan rumput yang terdapat pada petak percobaan antara lain: Axonophus compressus, Brachiaria mutica, Cynodon dactylon, Cyrtococcum oxyphyllum, Dactyloctenium aegyptium, Digitaria ciliaris, Echinochloa Colona, Eleusine indica, dan Paspalum conjugatum. Tabel 3 menunjukkan bahwa pada 2, 4, 8, dan 12 Minggu Setelah Aplikasi (MSA) seluruh perlakuan herbisida tidak mampu mengendalikan gulma rumput yang terdapat pada petak percobaan. Hal ini ditunjukkan oleh data bobot kering gulma golongan rumput pada seluruh petak percobaan perlakuan herbisida yang lebih tinggi dibandingkan dengan kontrol. Perlakuan mekanis mempu menekan pertumbuhan gulma rumput sebesar $93 \%$ pada 2 MSA dan $83 \%$ pada 12 MSA. Ketidakmampuan herbisida aminosiklopilaklor mengendalikan gulma rumput sesuai dengan pernyataan Finkelstein dkk. (2008) yang menyatakan bahwa herbisida aminosiklopilaklor sangat baik mengendalikan gulma berdaun lebar, tetapi kurang mampu mengendalikan gulma golongan rumput.

Selama percobaan berlangsung tidak ditemukan adanya gejala fitotoksisitas yang ditunjukkan oleh daun tua, daun muda dan buah tanaman kelapa sawit, baik berupa perubahan warna maupun bentuk pada $2,4,8$, dan 12 Minggu Setelah Aplikasi (MSA). Hal ini terjadi karena aplikasi herbisida yang dilakukan tidak mengenai daun tua, daun muda dan buah. Aplikasi dilakukan pada piringan kelapa sawit dengan target hanya pada gulma. Dengan tidak terjadinya fitotoksisitas pada daun tua dan muda, dapat diduga bahwa pertumbuhan dan produksi buah pada tanaman kelapa sawit ini tidak akan terganggu. Hal ini selaras dengan pernyataan Traore

Tabel 2. Bobot kering gulma golongan daun lebar (g per $\left.0,5 \mathrm{~m}^{2}\right)$.

\begin{tabular}{|c|c|c|c|c|c|c|c|c|c|c|}
\hline \multirow{3}{*}{ NO } & \multirow{3}{*}{ Perlakuan } & \multirow{3}{*}{ Dosis $\left(\mathrm{g} \mathrm{ha}^{-1}\right)$} & \multicolumn{2}{|c|}{2 MSA } & \multicolumn{2}{|c|}{$4 \mathrm{MSA}$} & \multicolumn{2}{|c|}{8 MSA } & \multicolumn{2}{|c|}{$12 \mathrm{MSA}$} \\
\hline & & & \multicolumn{8}{|c|}{ Data Transformasi } \\
\hline & & & \multicolumn{2}{|c|}{$\operatorname{trans} v(x+0.5)$} & \multicolumn{2}{|c|}{$\operatorname{trans} v(x+0.5)$} & \multicolumn{2}{|c|}{$\operatorname{trans} \mathrm{v}(\mathrm{x}+0.5)$} & \multicolumn{2}{|c|}{$\operatorname{tran} s \mathrm{v}(\mathrm{x}+0.5)$} \\
\hline 1 & Aminosiklopilaklor & 50 & 1,49 & $\mathrm{BC}$ & 1,55 & $\mathrm{BC}$ & 1,98 & $\mathrm{DE}$ & 1,64 & $\mathrm{D}$ \\
\hline 2 & Aminosiklopilaklor & 100 & 1,13 & $\mathrm{BC}$ & 1,07 & $\mathrm{C}$ & 1,25 & $\mathrm{E}$ & 2,76 & $\mathrm{CD}$ \\
\hline 3 & A minosiklopilaklor $+\mathrm{g}$ lifosat & $25+720$ & 1,24 & $\mathrm{BC}$ & 1,64 & $\mathrm{BC}$ & 7,44 & A & 6,08 & A \\
\hline 4 & A minosiklopilaklor + glifosat & $50+720$ & 2,14 & B & 1,92 & $\mathrm{BC}$ & 3,92 & CD & 6,00 & A \\
\hline 5 & Triklopir dan aminopiralid & 600 & 1,14 & $\mathrm{BC}$ & 2,75 & B & 5,20 & $\mathrm{BC}$ & 4,45 & B \\
\hline 6 & Mekanis & - & 0,86 & $\mathrm{C}$ & 1,20 & $\mathrm{BC}$ & 4,82 & $\mathrm{BC}$ & 3,39 & $\mathrm{BC}$ \\
\hline 7 & Kon trol & - & 5,07 & A & 5,26 & A & 6,63 & $\mathrm{AB}$ & 4,08 & B \\
\hline & BNT 0.05 & & 1,09 & & 1,66 & & 2,04 & & 1,23 & \\
\hline
\end{tabular}

Keterangan: Nilai tengah pada setiap kolom yang diikuti oleh huruf yang sama tidak berbeda nyata menurut uji BNT pada taraf $5 \%$. 
dkk. (2010) yang menyatakan bahwa herbisida glifosat tidak menyebabkan fitotoksisitas pada tanaman kelapa sawit. Hertharie dkk. (2007), menyatakan bahwa pada buah abnormal terjadi perubahan bentuk berupa adanya karpel tambahan pada buah. Selama percobaan berlangsung tidak ditemukan adanya gejala fitotoksisitas yang ditunjukkan pada buah tanaman kelapa sawit, baik berupa perubahan warna maupun bentuk buah sehingga seluruh perlakuan herbisida yang diaplikasikan tidak mempengaruhi pertumbuhan dan pembentukan buah tanaman kelapa sawit.

Bobot kering gulma total merupakan jumlah gulma yang terkendali dari gulma golongan daun lebar dan rumput. Berdasarkan hasil penelitian yang diperoleh menunjukan bahwa bobot kering gulma total memiliki korelasi positif dengan gulma golongan daun lebar tetapi berkorelasi negatif dengan gulma golongan rumput. Hal ini didasarkan pada hasil aplikasi herbisida aminosiklopilaklor $100 \mathrm{~g} \mathrm{ha}^{-1}$ dan kombinasi aminosiklopilaklor + glifosat dosis $25+720 \mathrm{~g} \mathrm{ha}^{-1}$ yang mampu mengendalikan gulma total hingga 4 minggu setelah aplikasi (MSA) dan mampu mengendalikan gulma daun lebar hingga $12 \mathrm{MSA}$, akan tetapi tidak mampu memngendalikan gulma golongan rumput.

Hasil penelitian menunjukkan bahwa pada 4 MSA perlakuan kombinasi herbisida aminosilklopilaklor + glifosat dosis $25+720 \mathrm{~g} \mathrm{ha}^{-1}$ dan triklopir + aminopiralid $216+384 \mathrm{~g} \mathrm{ha}^{-1}$ serta perlakuan penyiangan manual mampu mengendalikan pertumbuhan gulma total. Hal ini terlihat dari adanya penekanan yang tinggi terhadap pertumbuhan gulma total masing-masing sebesar 69, 81, dan $98 \%$ (Tabel 2). Sedangkan perlakuan herbisida yang lainnya tidak menunjukkan adanya perbedaan penekanan pertumbuhan gulma. Pada 4 MSA, aplikasi herbisida Aminosilkopilaklor $100 \mathrm{~g} \mathrm{ha}^{-1}$ mampu menekan pertumbuhan gulma hingga $80 \%$. Sedangkan perlakuan kombinasi herbisida aminosilklopilaklor dengan glifosat dosis $25+720,50+100 \mathrm{~g} \mathrm{ha}^{-1}$ dan perlakuan mekanis masing-masing mampu menekan pertumbuhan gulma total sebesar 79 dan $78 \%$ dan $98 \%$. Menurut Wibawa dkk. (2009), penggunaan herbisida glifosat cocok untuk mengendalikan gulma pada tanaman kelapa sawit dengan komposisi gulma yang beragam dan mampu mengendalikan gulma hingga 4 MSA.

Pada 8 dan 12 MSA, semua perlakuan herbisida sudah tidak mampu menekan pertumbuhan gulma. Hal ini terlihat dari bobot kering gulma total semua perlakuan herbisida yang lebih tinggi dari kontrol. Hanya perlakuan mekanis yang mampu mengendalikan gulma, hal ini dapat dilihat dari bobot kering gulma total perlakuan mekanis yang lebih rendah dibandingkan dengan dengan kontrol, dimana perlakuan mekanis pada 8 dan 12 MSA yang masih mampu menekan pertumbuhan gulma sebesar 68 dan $66 \%$.

Pengendalian gulma sangat penting untuk dilakukan dalam perkebunan kelapa sawit. Metode yang paling banyak digunakan adalah metode kimiawi dengan menggunakan herbisida. Berdasarkan hasil penelitian yang diperoleh, pengendalian gulma dengan menggunakan herbisida aminosiklopilaklor dosis 50 dan $100 \mathrm{~g} \mathrm{ha}^{-1}$ mampu mengendalikan gulma daun lebar hingga 12 MSA dan tidak menyebabkan keracunan baik pada daun muda, daun tua maupun pada buah. Sehingga, herbisida ini direkomendasikan kepada petani untuk mengendalikan gulma golongan daun lebar pada perkebunan kelapa sawit.

\section{KESIMPULAN}

Hasil penelitian menunjukan bahwa aplikasi herbisida aminosiklopilaklor tunggal dosis 50 dan $100 \mathrm{~g}$ ha $^{-1}$, kombinasi aminosiklopilaklor + glifosat dosis 25+720

Tabel 3. Bobot kering gulma golongan rumput $\left(\mathrm{g}\right.$ per $\left.0,5 \mathrm{~m}^{2}\right)$.

\begin{tabular}{|c|c|c|c|c|c|c|c|c|c|c|}
\hline \multirow{3}{*}{ NO } & \multirow{3}{*}{ Perlakuan } & \multirow{3}{*}{ Dosis $\left(\mathrm{g} \mathrm{ha}^{-1}\right)$} & \multicolumn{2}{|c|}{2 MSA } & \multicolumn{2}{|c|}{$4 \mathrm{MSA}$} & \multicolumn{2}{|c|}{$8 \mathrm{MSA}$} & \multicolumn{2}{|c|}{$12 \mathrm{MSA}$} \\
\hline & & & & & \multicolumn{6}{|c|}{ Data Tran sformasi } \\
\hline & & & & & \multicolumn{2}{|c|}{$\operatorname{trans} v(x+0.5)$} & \multicolumn{2}{|c|}{$\operatorname{tans} v(x+0.5)$} & \multicolumn{2}{|c|}{$\operatorname{trans} v(x+0.5)$} \\
\hline 1 & A minosiklopilaklor & 50 & 28,52 & A & 5,04 & A & 9,84 & A & 1,85 & A \\
\hline 2 & A minosiklopilaklor & 100 & 26,33 & A & 2,58 & $\mathrm{ABC}$ & 8,98 & $\mathrm{AB}$ & 1,75 & $A B$ \\
\hline 3 & Aminosiklopilaklor $+\mathrm{g}$ lifosat & $25+720$ & 14,75 & $\mathrm{AB}$ & 2,06 & $\mathrm{BC}$ & 4,77 & $\mathrm{CD}$ & 1,44 & $\mathrm{D}$ \\
\hline 4 & Aminosiklopilaklor + glifosat & $50+720$ & 30,11 & A & 1,86 & $\mathrm{BC}$ & 6,31 & $\mathrm{C}$ & 1,60 & $\mathrm{C}$ \\
\hline 5 & Triklopir dan aminopiralid & 600 & 8,43 & $\mathrm{AB}$ & 4,26 & $\mathrm{AB}$ & 9,14 & $\mathrm{AB}$ & 1,71 & B \\
\hline 6 & Mekanis & - & 0,93 & B & 0,76 & $\mathrm{C}$ & 2,52 & $\mathrm{D}$ & 1,39 & $\mathrm{D}$ \\
\hline 7 & Kontrol & - & 26,00 & A & 3,62 & $\mathrm{AB}$ & 6,85 & $\mathrm{BC}$ & 1,67 & $\mathrm{BC}$ \\
\hline & BNT 0.05 & & 23,39 & & 2,53 & & 2,53 & & 0,09 & \\
\hline
\end{tabular}

Keterangan: Nilai tengah pada setiap kolom yang diikuti oleh huruf yang sama tidak berbeda nyata menurut uji BNT pada taraf $5 \%$. 
$\mathrm{g} \mathrm{ha}^{-1}$ dan 50+720 $\mathrm{g} \mathrm{ha}^{-1}$, dan triklopir + aminopiralid $216+384 \mathrm{~g} \mathrm{ha}^{-1}$ pada perkebunan kelapa sawit tidak meracuni dan tidak mempengaruhi tinggi tanaman kelapa sawit belum menghasilkan; aplikasi herbisida aminosiklopilaklor $100 \mathrm{~g} \mathrm{ha}^{-1}$ dan kombinasi aminosiklopilaklor + glifosat dosis $25+720 \mathrm{~g} \mathrm{ha}^{-1}$ mampu mengendalikan gulma total hingga 4 minggu setelah aplikasi; aplikasi herbisida aminosiklopilaklor 50 dan 100 $\mathrm{g} \mathrm{ha}^{-1}$ mampu mengendalikan gulma daun lebar hingga 12 minggu setelah aplikasi, tetapi semua perlakuan herbisida tidak mampu mengendalikan gulma rumput dan; aplikasi herbisida aminosiklopilaklor 50 dan $100 \mathrm{~g} \mathrm{ha}^{-1}$ mampu mengendalikan gulma dominan Richardia brasiliensis hingga 8 minggu setelah aplikasi, tetapi tidak mampu mengendalikan gulma dominan Dactyloctenium aegyptium.

\section{DAFTAR PUSTAKA}

Anderson, W. P. 1977. Weed Science Principles. West Publishing Co. New York.

Barus, E. 2007. Pengendalian Gulma Di Perkebunan : Efektivitas dan Efisiensi Aplikasi Herbisida. Kanisius. Yogyakarta. 105 hal.

Ditjenbun. 2008. Pendataan Kelapa Sawit Tahun 2008 secara Komprehensif dan Objektif. http:/ /ditjenbun.deptan.go.id. Diakses pada tanggal 14 November 2012.

Finkelstein, B. L., G. R. Armel, S. A. Bolgunas, D. A. Clark, J. S. Claus, R. J. Crosswicks, C. M. Hirata, G. J. Hollingshaus, M. K. Koeppe, P. L. Rardon,V.A. Wittenbach, and M.D. Woodward. 2008. Discovery of aminocyclopyrachlor (proposed common name) (DPX-MAT28): A new broad-spectrum auxinic herbicide. Abstracts of Papers, 236th ACS National Meeting, Philadelphia, PA, United States, August 17-21, 2008.

Hetharie, H., G. A.Wattimena, M. Thenawidjaya, H. Aswidinnoor, N. T. Mathius dan G. Ginting. 2007. Karakterisasi Morfologi Bunga dan Buah Abnormal Kelapa Sawit (Elaeis guineensis Jacq.) Hasil Kultur Jaringan1. Bul. Agron. 35 (1): $50-57$

Mohamad, R. B., W. Wibawa, M. G. Mohayidin, A. B. Puteh, A. S. Juraimi, Y. Awang, and M. B. M. Lassim. 2010. Management of Mixed Weeds in Young Oil-palm Plantation with Selected BroadSpectrum Herbicides. Pertanika J. Trop. Agric. Sci. 33 (2): 193 - 203.

Traore, K., D. Soro, B. Camara, and F. Sorho. 2010. Effectiveness of Glyphosate Herbicide in a Juvenile Oil Palm Plantation in Côte D'ivoire. journal of animal \& plant sciences, 6 (1): 559566.

Tu, M., C. Hurd, R. Robinson, and J. M. Randall. 2001. Weed Control Methods Handbook. http:// www.invasive.org/gist/products/handbook/ 20.Triclopyr.pdf. Diakses tanggal 17 November 2012.

Wibawa, W., R. Mohamad, A. S. Juraimi, D. Omar, M. G. Mohayidin, and M. Begum. 2009. Weed control efficacy and short term weed dynamic impact of three non-selective herbicides in immature oil palm plantation. Int. J. Agric. Biol. 11: 145-150 